\title{
Identification of Biomarkers for Non-small-cell Lung Cancer Patients Treated With an Immune Checkpoint Inhibitor
}

\author{
SOUSUKE KUBO ${ }^{1}$, NOBUAKI KOBAYASHI ${ }^{1}$, KOHEI SOMEKAWA ${ }^{2}$, MOMO HIRATA $^{2}$, \\ CHISATO KAMIMAKI $^{1}$, HIROKO AIKO ${ }^{3}$, SEIGO KATAKURA $^{1}$, SHUHEI TERANISHI ${ }^{1}$, \\ KEISUKE WATANABE ${ }^{1}$, YU HARA ${ }^{1}$, MASAKI YAMAMOTO ${ }^{2}$, MAKOTO KUDO $^{2}$ and TAKESHI KANEKO ${ }^{1}$ \\ ${ }^{1}$ Department of Pulmonology, Yokohama City University Graduate School of Medicine, Yokohama, Japan; \\ ${ }^{2}$ Respiratory Disease Center, Yokohama City University Medical Center, Yokohama, Japan; \\ ${ }^{3}$ Department of Pulmonology, Yokohama Rosai Hospital, Yokohama, Japan
}

\begin{abstract}
Background/Aim: Immune checkpoint inhibitors (ICIs) have an important role in lung cancer therapy. Although the programmed cell death protein-1 (PD-L1) tumor proportion score (TPS) and tumor mutational burden are known prognostic factors, they are insufficient to predict clinical outcomes. This study was conducted to identify novel biomarkers for ICI treatment. Patients and Methods: We performed univariable and multivariable analyses of 110 patients with advanced non-small-cell lung cancer (NSCLC) who were treated with an ICI to identify novel biomarkers related to prognosis. We assessed their backgrounds, such as performance status (PS), PD-L1 TPS, smoking status, and peripheral white blood cell counts at baseline and on the day the second course of ICI administration. Results: In the multivariable analysis, PS, driver gene, immune-related adverse events, and post-treatment absolute neutrophil counts (post-ANCs) were significantly associated with progressionfree survival. Conclusion: A high level of post-ANCs was associated with poor outcome in ICI-treated NSCLC patients.
\end{abstract}

Emergence of immune checkpoint inhibitors (ICIs), such as nivolumab, pembrolizumab, and atezolizumab, has led to a paradigm shift in the treatment of non-small-cell lung cancer (NSCLC). Although the combination of ICIs and cytotoxic

This article is freely accessible online.

Correspondence to: Nobuaki Kobayashi, Yokohama City University Graduate School of Medicine, Fukuura 3-9 Kanazawa-Ku, Yokohama, Kanagawa, 236-0004 Japan. Tel: +81 457872800, Fax: +81 457872931, e-mail: nkobayas@yokohama-cu.ac.jp

Key Words: Immune checkpoint inhibitor, non-small-cell lung carcinoma, predictive factor, neutrophil counts, tumor-associated neutrophils. agents has been recently adapted for first-line chemotherapy regardless of the programmed cell death protein-1 (PD-L1) tumor proportion score (TPS) (1), ICI monotherapy remains the standard therapy for NSCLC patients with PD-L1 high expression (2). The PD-L1 TPS and tumor mutational burden (TMB) are known major predictive markers for ICI (3-5). Among patients with $\geq 50 \%$ PD-L1 expression, the response rate to pembrolizumab monotherapy has been found to be $45.2 \%$, whereas among patients with $<1 \%$ PD-L1 expression, the response rate of pembrolizumab monotherapy was $7.8 \%$ (6). Although the PD-L1 TPS is an important biomarker for ICI, high expression of PD-L1 is not always observed in patients who are successfully treated with an ICI. In a certain number of patients with the risk of immune-related adverse events (irAEs), ICIs provide no clinical benefit. Thus, more effective and easily measurable biomarkers for ICI are needed for clinical use.

Some biomarkers assessed in the peripheral blood of ICItreated patients have previously been reported. High lactate dehydrogenase (LDH) and high C-reactive protein (CRP) at baseline have been reported to be associated with poor outcome $(7,8)$. High neutrophil-lymphocyte ratio (NLR) $(9$, 10), high absolute lymphocyte counts (ALCs), high absolute eosinophil counts (AECs), and high absolute neutrophil counts (ANCs) prior to induction of ICI have been shown to be associated with progression-free survival (PFS) and overall survival (OS) in NSCLC patients (11). Clinical biomarkers, poor performance status (PS) $(9,12)$, appearance of any irAEs (13), and expression of driver gene mutation (14) have also been reported to be associated with poor prognosis in NSCLC patients.

The aim of this study was to identify biomarkers associated with PFS of ICI-treated patients by retrospective analysis of blood peripheral biomarkers at baseline and on the day of the second course of ICI administration and to analyze the patients' backgrounds. 


\section{Patients and Methods}

Patients. This retrospective review was conducted by reviewing the medical records of all patients with advanced or recurrent NSCLC who received an ICI, including nivolumab, pembrolizumab, or atezolizumab, at Yokohama City University Medical Center and Yokohama City University Hospital between January 2016 and December 2018. The inclusion criteria were $>18$ years old, and patients who received at least one dose of nivolumab, pembrolizumab, or atezolizumab. The exclusion criterion was any complication involving obvious infection at baseline. If the patient received more than two regimens of ICIs, the first ICI used was selected for analysis. If the patient could not continue the ICI treatment before receiving blood tests on the day of administering the second course of an ICI, then we only included the analysis of the patient's background and did not include the analysis of the white blood cell (WBC) count fraction on the day of the second course of ICI administration.

All patients provided written informed consent for use of their clinical and biological data for the purpose of this scientific research. The study was performed according to protocols approved by our institutional review board (B191200044).

Treatment regimens. Nivolumab was administered intravenously at a dose of $3 \mathrm{mg} / \mathrm{kg}$ every 2 weeks, pembrolizumab was administered intravenously at a dose of $200 \mathrm{mg} /$ body every 3 weeks, and atezolizumab was administered intravenously at a dose of 1200 $\mathrm{mg}$ /body every 3 weeks.

Statistical methods. The patients' baseline characteristics and adverse events were extracted from their medical records for review. Furthermore, the fraction of WBCs (ANCs, ALCs, AECs, and absolute monocyte counts), NLR, neutrophil to monocyte ratio, lymphocyte to monocyte ratio, and the sum of neutrophil counts and monocyte counts at baseline and the day the second course of ICI was administered were obtained. We set the median values as the cutoff values for blood cell counts. PFS was measured from induction of the first course of ICI to progressive disease defined according to the Response Evaluation Criteria in Solid Tumors version 1.1 or death from any cause. In the univariable analysis, Kaplan-Meyer analysis was performed with the log-rank test to identify any relationships between PFS and the above factors. A Cox proportional hazards model was used in the multivariable analysis with the factors significantly associated with PFS in the univariable analysis. A $p$-value of $<0.05$ was considered to be indicative of statistical significance. All statistical analyses were performed by using JMP ${ }^{\circledR}$ Pro 12 software (SAS Institute Inc., Cary, NC, USA).

\section{Results}

Baseline characteristics. A total of 413 lung cancer patients were assessed for eligibility (Figure 1). Fifty-four patients with small-cell lung cancer and 247 patients who were not treated with an ICI regimen were excluded. Additionally, 2 patients each were excluded because of the complication of an obvious infection at the initiation of ICI and for death on day 1 due to the complication. One hundred and 10 patients were included in the analysis of the baseline characteristics of the patients. Furthermore, 2 patients were excluded because they did not have a blood test on the day the second course of ICI was administered with irAEs. One hundred and 8 patients were analyzed for the fraction of WBCs on the day the second course of ICI was administered. Because one patient received two regimens of ICIs (nivolumab at the second course and atezolizumab at the fifth course), the first use of ICI was selected for analysis.

Baseline epidemiological characteristics are summarized in Table I. The median age was 70 years (range $=34-82$ years). Eighty-five patients were male. There were 42 patients with a PS of 0,56 with a PS of 1,9 with a PS of 2, and 3 with a PS of 3 . Forty-seven patients received pembrolizumab, 57 received nivolumab, and 6 received atezolizumab. Thirty-six patients had a PD-L1 TPS $\geq 50 \%$, 18 had a TPS of $1 \%$ to $49 \%, 16$ had a TPS $<1 \%$, and $40 \mathrm{had}$ an unknown TPS. The histological subtypes were adenocarcinoma in 71 patients, squamous cell carcinoma in 26, adenosquamous carcinoma in 2, NSCLC in 3, undifferentiated carcinoma in 2 , and pleomorphic in 1 . Eleven patients had driver gene mutation-positive lung cancer [10 were epidermal growth factor receptor (EGFR) gene positive, and one was echinoderm microtubuleassociated protein-like 4 anaplastic lymphoma kinase fusion gene positive], whereas 99 patients had driver gene mutation-negative lung cancer.

Univariable analysis of parameters associated with PFS. To identify biomarkers of PFS, we examined the baseline patients' characteristics and peripheral blood markers. Kaplan-Meier analysis revealed statistically significant relationships between the following biomarkers and better PFS: PS 0-1 (vs. 2-3, $p<0.0001$ ), PD-L1 TPS $\geq 50 \%$ (vs. 0\%$49 \%$ or unknown), driver gene negative (vs. positive, $p=0.0303)$, pack-year of smoking $>20$ ( $v s . \leq 20, p=0.0403)$, no liver metastasis ( $v s$. any, $p=0.0453$ ), any irAEs ( $v s$. none, $p<0.0001)$, low LDH ( $v s$. high LDH, $p=0.0425)$, low CRP (vs. high CRP, $p=0.045$ ), low post-treatment ANCs (postANCs) ( $v s$. high post-ANCs, $p=0.0093$ ), and low posttreatment NLR (post-NLR) ( $v s$. high post-NLR, $p=0.0121$ ). Pre-treatment of the NLR (pre-NLR) was not significantly associated with PFS in this study (Table II, Figure 2).

Multivariable analysis of parameters associated with PFS. Multivariable Cox proportional hazards analysis was performed. PS, PD-L1 TPS, driver gene, and any irAEs, which were significantly associated with PFS in the univariable analysis, were used as parameters in the multivariable analysis. Furthermore, PS, PD-L1 TPS, driver gene, and irAEs have previously been reported to be associated with PFS and OS in ICI-treated patients $(2,9,15$, 16). Post-ANC was chosen as a parameter for use in the multivariable analysis because tumor-associated neutrophils (TANs) have been reported to affect the tumor-immune 


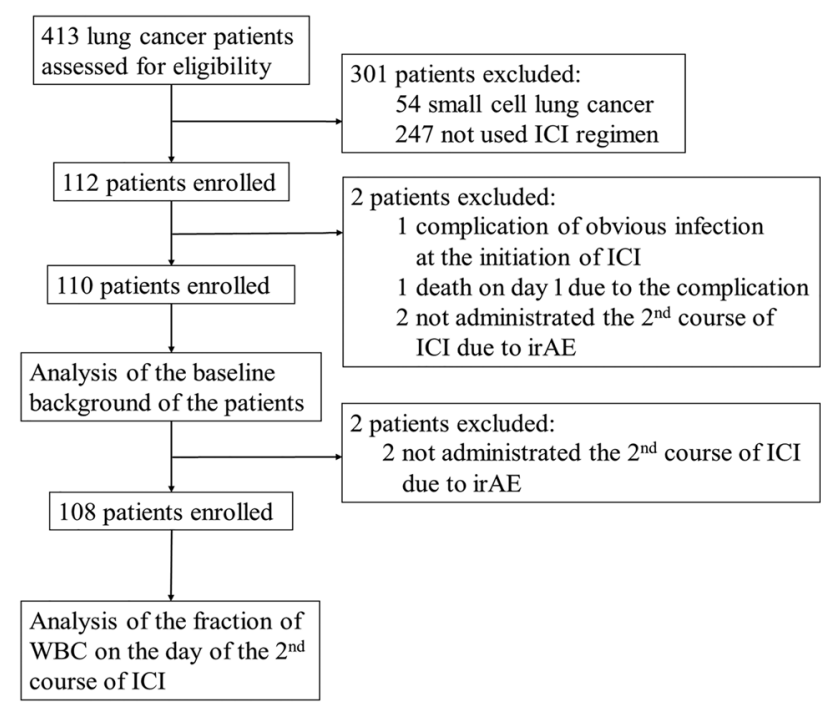

Figure 1. A total of 413 lung cancer patients were assessed for eligibility. Fifty-four patients with small-cell lung cancer and 247 patients not treated with an immune checkpoint inhibitor (ICI) regimen were excluded. One patient was excluded because of the complication of an obvious infection at ICI initiation. One patient died on day 1 because of the complication. One hundred and 10 patients were included to assess the patients' background. Furthermore, 2 patients were excluded because they did not have blood tests on the day the second course of ICIs was administered because of immune related adverse events (irAEs). One hundred and 8 patients were analyzed for the fraction of WBCs on the day the second course of ICIs was administered. Because one patient received two regimens of ICIs, we only selected the first use of ICIs for the analysis. WBC: White blood cells.

environment in previous studies $(17,18)$, and a sustained high level of ANCs during ICI administration was thought to more likely reflect the role of TANs. In this multivariable analysis, PS, driver gene, irAEs, and post-ANCs were significantly associated with PFS (PS: HR $=0.41$, $95 \% \mathrm{CI}=0.19-0.88, p=0.022$; driver gene positive: $\mathrm{HR}=0.29$, $95 \% \mathrm{CI}=0.12-0.67, p=0.004$; occurring any irAEs: $\mathrm{HR}=0.43$, $95 \% \mathrm{CI}=0.24-0.76, p=0.019$; post-ANCs $\leq 4,800$ : $\mathrm{HR}=0.54$, $95 \% \mathrm{CI}=0.32-0.90, p=0.004$ ) (Table III).

\section{Discussion}

Expression of PD-L1 in NSCLC is the most useful biomarker for the treatment with ICIs in the clinical sites. However, some NSCLC patients with a high level of PD-L1 TPS showed no response to treatment with ICIs, which was due several issues in the method of measuring PD-L1 TPS. It is known that PD-L1 expression varies among different parts of biopsy specimens from the same tumor tissue (19). Furthermore, a previous study has shown that PD-L1 expression was changed before and after treatment with
Table I. Baseline epidemiological characteristics.

\begin{tabular}{|c|c|c|c|}
\hline \multirow[b]{2}{*}{ Parameter } & & \multicolumn{2}{|c|}{ Total $(\mathrm{N}=110)$} \\
\hline & & $\mathrm{N}$ & $\%$ \\
\hline \multirow[t]{2}{*}{ Age (years) } & $<70$ & 48 & 43.6 \\
\hline & $\geq 70$ & 62 & 56.4 \\
\hline \multirow[t]{2}{*}{ Gender } & Male & 85 & 77.3 \\
\hline & Female & 25 & 22.7 \\
\hline \multirow[t]{2}{*}{ BMI $\left(\mathrm{kg} / \mathrm{m}^{2}\right)$} & $>22$ & 74 & 67.3 \\
\hline & $\leq 22$ & 36 & 32.7 \\
\hline \multirow[t]{4}{*}{ PS } & 0 & 42 & 38.2 \\
\hline & 1 & 56 & 50.9 \\
\hline & 2 & 9 & 8.2 \\
\hline & 3 & 3 & 2.7 \\
\hline \multirow[t]{3}{*}{ Medicine } & Nivolumab & 57 & 51.8 \\
\hline & Pembrolizumab & 47 & 42.7 \\
\hline & Atezolizumab & 6 & 5.5 \\
\hline \multirow[t]{4}{*}{ Pathology } & Ad & 71 & 64.5 \\
\hline & $\mathrm{Sq}$ & 26 & 23.6 \\
\hline & $\mathrm{Ad}+\mathrm{Sq}$ & 2 & 1.8 \\
\hline & Other & 11 & 10.0 \\
\hline PD-L1 & $\geq 50$ & 36 & 32.7 \\
\hline \multirow[t]{3}{*}{ TPS (\%) } & $1-49$ & 18 & 16.4 \\
\hline & $<1$ & 16 & 14.5 \\
\hline & NA & 40 & 36.4 \\
\hline \multirow[t]{2}{*}{ Metastasis } & Brain & 27 & 24.5 \\
\hline & Liver & 13 & 11.8 \\
\hline \multirow[t]{4}{*}{ Line } & 1 & 27 & 24.5 \\
\hline & 2 & 40 & 36.4 \\
\hline & 3 & 22 & 20.0 \\
\hline & $\geq 4$ & 21 & 19.1 \\
\hline Smoking & $\geq 20$ & 74 & 67.3 \\
\hline \multirow[t]{2}{*}{ (pack-year) } & $>0, \leq 20$ & 16 & 14.5 \\
\hline & 0 & 20 & 18.2 \\
\hline \multirow[t]{3}{*}{ SUV max } & $>9.9$ & 40 & 36.4 \\
\hline & $\leq 9.9$ & 38 & 34.5 \\
\hline & NA & 32 & 29.1 \\
\hline \multirow[t]{2}{*}{ Driver gene mutation } & Positive & 11 & 10.0 \\
\hline & Negative & 99 & 90.0 \\
\hline
\end{tabular}

BMI, Body mass index; PS, performance status; Ad, adenocarcinoma; Sq, squamous cell carcinoma; PD-L1, Programmed death-ligand 1; TPS, tumor proportion score; SUV max, maximum standardized uptake value.

cisplatin in patients with head and neck carcinoma (20). Regarding TMB, PFS was significantly longer with first-line nivolumab plus ipilimumab than with chemotherapy among the NSCLC patients with high TMB (5). However, the TMB cannot be checked at clinical sites during first-line chemotherapy. Therefore, there is a need for biomarkers indicative of ICI efficacy.

The benefits of estimating prognosis with peripheral blood markers are the reduced burden on the patients and ease of repeated measurements. Performing re-biopsy is sometimes difficult, whereas peripheral blood biomarkers can be estimated repeatedly during the treatment of lung cancer. Regarding PDL1, it has been reported that the expression of PD-L1 in 
Table II. Baseline patients' characteristics and peripheral blood markers to identify candidates for biomarkers of PFS.

\begin{tabular}{|c|c|c|c|c|}
\hline Parameter & Category & Median PFS & $95 \% \mathrm{CI}$ & $p$-Value (Log-rank) \\
\hline \multirow[t]{2}{*}{ Gender } & Male & 183 & $68-410$ & \\
\hline & Female & 93 & $51-\mathrm{NE}$ & 0.5518 \\
\hline \multirow{3}{*}{ Type of ICI } & Pembrolizumab & 285 & 78-NE & \\
\hline & Nivolumab & 93 & $62-247$ & \\
\hline & Atezolizumab & 54.7 & $13-\mathrm{NE}$ & 0.1683 \\
\hline \multirow[t]{2}{*}{ Line number } & 1 & 95 & $63-192$ & \\
\hline & $\geq 2$ & 323 & 78-NE & 0.0822 \\
\hline \multirow[t]{2}{*}{ Age (years) } & $>70$ & 247 & $97-\mathrm{NE}$ & \\
\hline & $\leq 70$ & 78 & $59-192$ & 0.1686 \\
\hline \multirow[t]{2}{*}{ PS } & $0-1$ & 168 & $83-410$ & \\
\hline & $2-3$ & 40.5 & $25-51$ & $<0.0001$ \\
\hline \multirow[t]{2}{*}{ PD-L1 TPS (\%) } & $\geq 50$ & 410 & $119-\mathrm{NE}$ & \\
\hline & $0-49$ or NA & 83 & $62-168$ & 0.0303 \\
\hline \multirow[t]{2}{*}{ Driver gene } & Positive & 33 & $25-50$ & \\
\hline & Negative & 168 & $83-323$ & 0.0002 \\
\hline \multirow[t]{2}{*}{ SUV max } & $>9.85$ & 183 & $63-\mathrm{NE}$ & \\
\hline & $\leq 9.85$ & 168 & 78-NE & 0.5223 \\
\hline \multirow[t]{2}{*}{ Smoking (pack-year) } & $>20$ & 247 & $95-716$ & \\
\hline & $\leq 20$ & 75 & $51-102$ & 0.0403 \\
\hline \multirow[t]{2}{*}{ BMI $\left(\mathrm{kg} / \mathrm{m}^{2}\right)$} & $>22$ & 192 & $63-590$ & \\
\hline & $\leq 22$ & 95 & $65-267$ & 0.3549 \\
\hline \multirow{2}{*}{ Brain metastasis } & Any & 78 & $51-192$ & \\
\hline & None & 128 & $75-590$ & 0.4034 \\
\hline \multirow{2}{*}{ Liver metastasis } & Any & 46 & $32-285$ & \\
\hline & None & 138 & $78-410$ & 0.0453 \\
\hline \multirow[t]{2}{*}{ Operation } & Any & 126 & $65-590$ & \\
\hline & None & 138 & $63-410$ & 0.7614 \\
\hline \multirow[t]{2}{*}{ Adverse event } & Any & $\mathrm{NE}$ & 168-NE & \\
\hline & None & 65 & $50-102$ & $<0.0001$ \\
\hline \multirow[t]{2}{*}{ LDH } & $>211$ & 76 & $49-247$ & \\
\hline & $\leq 211$ & 168 & $93-716$ & 0.0425 \\
\hline \multirow[t]{2}{*}{ CRP } & $>0.68$ & 68 & $47-267$ & \\
\hline & $\leq 0.68$ & 192 & $83-716$ & 0.045 \\
\hline Pre-ANCs & $>4374$ & 119 & $62-323$ & \\
\hline & $\leq 4374$ & 128 & $63-590$ & 0.7043 \\
\hline Post-ANCs & $>4800$ & 78 & $51-126$ & \\
\hline & $\leq 4800$ & 410 & $82-716$ & 0.0093 \\
\hline Pre-ALCs & $>1340$ & 138 & $75-590$ & \\
\hline & $\leq 1340$ & 95 & $56-247$ & 0.2849 \\
\hline Post-ALCs & $>1300$ & 192 & $63-590$ & \\
\hline & $\leq 1300$ & 95 & $63-247$ & 0.3866 \\
\hline Pre-AMCs & $>566.6$ & 119 & $62-323$ & \\
\hline & $\leq 566.6$ & 128 & $68-590$ & 0.6354 \\
\hline Post-AMCs & $>590$ & 83 & $51-247$ & \\
\hline & $\leq 590$ & 168 & $78-716$ & 0.0788 \\
\hline Pre-AECs & $>35.8$ & 126 & $65-\mathrm{NE}$ & \\
\hline & $\leq 35.8$ & 128 & $63-\mathrm{NE}$ & 0.902 \\
\hline Post-AECs & $>151.8$ & 97 & $59-\mathrm{NE}$ & \\
\hline & $\leq 151.8$ & 247 & $63-\mathrm{NE}$ & 0.718 \\
\hline Pre-NLRs & $>3.45$ & 97 & $56-285$ & \\
\hline & $\leq 3.45$ & 128 & $63-\mathrm{NE}$ & 0.2819 \\
\hline Post-NLRs & $>3.61$ & 78 & $49-128$ & \\
\hline & $\leq 3.61$ & 285 & $119-\mathrm{NE}$ & 0.0121 \\
\hline Pre-NMRs & $>7.56$ & 102 & $65-285$ & \\
\hline & $\leq 7.56$ & 126 & $63-\mathrm{NE}$ & 0.4956 \\
\hline Post-NMRs & $>8.20$ & 97 & $59-247$ & \\
\hline & $\leq 8.20$ & 183 & $65-410$ & 0.4763 \\
\hline $\mathrm{L}+\mathrm{M}$ pre & $>2035$ & 126 & $63-590$ & \\
\hline & $\leq 2035$ & 128 & $68-267$ & 0.828 \\
\hline$L+M$ post & $>1979$ & 168 & $63-590$ & \\
\hline
\end{tabular}

BMI: Body mass index; PS: performance status; Ad: adenocarcinoma; Sq: squamous cell carcinoma; PD-L1: Programmed death-ligand 1; TPS: tumor proportion score; SUV max: maximum standardized uptake value; ANC: absolute neutrophil counts; ALC: absolute lymphocyte counts; AMC: absolute monocyte counts; AEC: absolute NLR: neutrophil-to-lymphocyte ratio; neutrophil to monocyte ratio; L: lymphocyte; M: monocyte; NMR: neutrophil-to-monocyte ratio. 

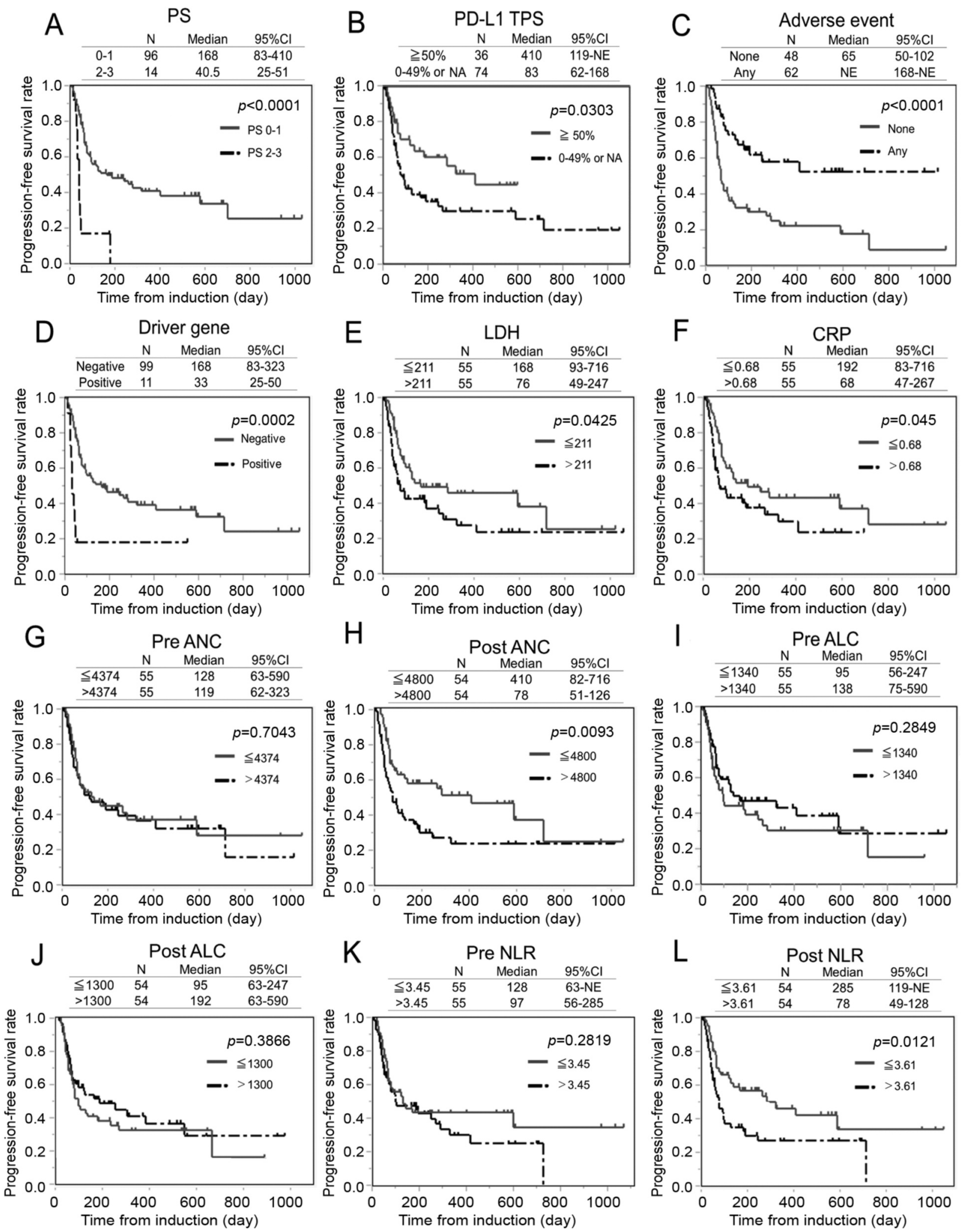

Figure 2. Kaplan-Meier analysis of PS, PD-L1, adverse event, driver gene, baseline LDH and CRP, pre-and post-ANCs, pre-and post-ALCs, and pre- and post-NLRs. PS: Performance status; PD-L1: programmed death-ligand 1; TPS: tumor proportion score; LDH: lactate dehydrogenase; CRP: C reactive protein; ANC: absolute neutrophil counts; ALC: absolute neutrophil counts; NLR: neutrophil-to-lymphocyte ratio. 
Table III. Multivariable Cox proportional hazards analysis results.

\begin{tabular}{lllll}
\hline Parameter & Category & HR & $95 \%$ CI & $p$-Value (Log-rank) \\
\hline PS & $0-1(v s .2-3)$ & 0.41 & $0.19-0.88$ & 0.031 \\
PD-L1 TPS & $\geq 50 \%(v s .<49 \%$ or NA) & 0.61 & $0.33-1.09$ & 0.084 \\
Driver gene & Negative $(v s$. Positive) & 0.29 & $0.12-0.67$ & 0.008 \\
Adverse event & Any $(v s$. Never) & 0.43 & $0.24-0.76$ & 0.003 \\
Post-ANCs & $>4800(v s . \leq 4800)$ & 0.54 & $0.32-0.90$ & 0.018 \\
\hline
\end{tabular}

PS: Performance status; PD-L1: programmed death-ligand 1; TPS: tumor proportion score; ANC: absolute neutrophil counts.

circulating tumor cells (CTCs) did not correlate with that in tumor tissues, and the expression of PD-L1 in CTCs only inversely correlated with PFS for 6 months (21). In another study, a high level of soluble PD-L1 was associated with poor PFS and OS in patients with NSCLC being treated with nivolumab (22). However, soluble PD-L1 cannot be estimated at clinical sites. Similarly, some serum markers including interferon- $\gamma(\mathrm{IFN}-\gamma)$, tumor necrosis factor-alpha (TNF- $\alpha)$, and indoleamine 2,3-dioxygenase (IDO), which were reported to be useful as biomarkers for the treatment with ICI, cannot be measured in the clinical setting (23-25). On the other hand, the fraction of WBCs is measurable at clinical sites. In a previous study, baseline levels of NLR, ANCs, ALCs, and AECs have been reported to be associated with PFS and OS in patients treated with ICIs $(11,26)$. Furthermore, NLR after ICI treatment has been shown to be associated with PFS and OS (27). The results of these studies suggest that peripheral blood cells were related in some way to the effect of ICI treatment.

In the present study's analysis, PS, driver gene, any irAEs, and post-ANCs were significantly associated with PFS. In a meta-analysis of five Phase III trials comparing ICIs (nivolumab, pembrolizumab, atezolizumab), and docetaxel for advanced NSCLC, the EGFR wild-type group showed significantly better OS, but there was no significant difference in OS of the EGFR-positive group between ICIs and docetaxel (28), which was similar to the results of our current study. The cause is not clear yet, but EGFR-positive patients may have fewer effective tumor antigens for ICIs because there are only a few mutations except for the EGFR mutation. Although the mechanism is not clear, previous reports have suggested that irAEs are associated with the efficacy of ICIs in melanoma $(13,29,30)$ and NSCLC (16). These results are consistent with those of our report. An association between a low-level of post-ANCs with good PFS in multivariable analysis in NSCLC patients has not been previously reported. In other words, elevation of neutrophil counts after ICI was associated with poor prognosis or a decrease in neutrophil counts was associated with good prognosis. It has been suggested that the effect of IFN- $\gamma$ after treatment with ICI involves the expression of PD-L1 and repression of the proliferation of lymphocytes (31). Post-ANCs cannot be estimated at initiation of ICIs. However, if the efficacy of ICI treatment is estimated just before induction of the second course of an ICI, we can change the regimen without delay and identify pseudoprogression at an early stage.

Neutrophils are traditionally considered to have a role in defense against infections, such as bacteria. Recently, neutrophils have been gradually found to have pro-tumoral functions in cancer immunity. TANs are related to tumor progression, angiogenesis, and metastasis by secreting vascular endothelial growth factor, matrix metalloproteinase 9, and Bv8 (32-34). TANs secrete transforming growth factor $\beta$, which causes epithelial-mesenchymal transition and induces differentiation of regulatory T cells (33). TANs also produce arginine 1 , which decreases the function of $\mathrm{T}$ cells (35). Our study results suggest that neutrophil counts of peripheral blood after induction with ICIs are related to prognosis, but the relationship between neutrophil counts of peripheral blood and TANs is unclear.

There are several limitations in this study that need to be considered. We did not investigate OS because of the lack of medical recording. Compared with the responses to commonly used anticancer drugs, the responses to ICI treatment might show variable patterns, such as pseudoprogression. However, the association between PFS/OS and ICIs in patients with advanced solid tumors has been reported in a previous meta-analysis (36), so investigation of the relationships among PFS and prognostic factors was justified. The lack of a control group of patients who had not received ICIs is another study limitation.

\section{Conclusion}

Poor PS, presence of driver gene, any irAEs, and a high level of post-ANCs were associated with poor outcome in patients with NSCLC who received ICIs. A prospective study of factors predictive of ICI efficacy is needed.

\section{Conflicts of Interest}

The Authors have no conflicts of interest to declare regarding this study. 


\section{Authors' Contributions}

Conception and design: SK and NK. Acquisition of data: SK, KS, $\mathrm{MH}, \mathrm{CK}, \mathrm{HA}, \mathrm{SK}, \mathrm{ST}, \mathrm{KW}, \mathrm{YH}$, and MY. Analysis and interpretation of data: SK, and NK. Writing, review, and/or revision of the manuscript: SK, NK, MK and TK.

\section{Acknowledgements}

The Authors would like to express their gratitude to Dr. Yuusuke Saigusa of the Department of Biostatistics, Yokohama City University School of Medicine, for his guidance and help.

\section{References}

1 Gandhi L, Rodriguez-Abreu D, Gadgeel S, Esteban E, Felip E, De Angelis F, Domine M, Clingan P, Hochmair MJ, Powell SF, Cheng SY, Bischoff HG, Peled N, Grossi F, Jennens RR, Reck M, Hui R, Garon EB, Boyer M, Rubio-Viqueira B, Novello S, Kurata T, Gray JE, Vida J, Wei Z, Yang J, Raftopoulos H, Pietanza MC, Garassino MC and Investigators K-: Pembrolizumab plus chemotherapy in metastatic non-small-cell lung cancer. N Engl J Med 378(22): 20782092, 2018. PMID: 29658856. DOI: 10.1056/NEJMoa1801005

2 Reck M, Rodriguez-Abreu D, Robinson AG, Hui R, Csoszi T, Fulop A, Gottfried M, Peled N, Tafreshi A, Cuffe S, O'Brien M, Rao S, Hotta K, Leiby MA, Lubiniecki GM, Shentu Y, Rangwala R, Brahmer JR and Investigators K-: Pembrolizumab versus chemotherapy for pd-11-positive non-small-cell lung cancer. N Engl J Med 375(19): 1823-1833, 2016. PMID: 27718847. DOI: 10.1056/NEJMoa1606774

3 Rizvi H, Sanchez-Vega F, La K, Chatila W, Jonsson P, Halpenny D, Plodkowski A, Long N, Sauter JL, Rekhtman N, Hollmann T, Schalper KA, Gainor JF, Shen R, Ni A, Arbour KC, Merghoub T, Wolchok J, Snyder A, Chaft JE, Kris MG, Rudin CM, Socci ND, Berger MF, Taylor BS, Zehir A, Solit DB, Arcila ME, Ladanyi M, Riely GJ, Schultz N and Hellmann MD: Molecular determinants of response to anti-programmed cell death (pd)-1 and antiprogrammed death-ligand 1 (pd-11) blockade in patients with nonsmall-cell lung cancer profiled with targeted next-generation sequencing. J Clin Oncol 36(7): 633-641, 2018. PMID: 29337640. DOI: $10.1200 / \mathrm{JCO} .2017 .75 .3384$

4 Rittmeyer A, Barlesi F, Waterkamp D, Park K, Ciardiello F, von Pawel J, Gadgeel SM, Hida T, Kowalski DM, Dols MC, Cortinovis DL, Leach J, Polikoff J, Barrios C, Kabbinavar F, Frontera OA, De Marinis F, Turna H, Lee JS, Ballinger M, Kowanetz M, He P, Chen DS, Sandler A and Gandara DR: Atezolizumab versus docetaxel in patients with previously treated non-small-cell lung cancer (oak): A phase 3, open-label, multicentre randomised controlled trial. Lancet 389(10066): 255-265, 2017. PMID: 27979383. DOI: 10.1016/S0140-6736(16)32517-X

5 Hellmann MD, Ciuleanu TE, Pluzanski A, Lee JS, Otterson GA, Audigier-Valette C, Minenza E, Linardou H, Burgers S, Salman P, Borghaei H, Ramalingam SS, Brahmer J, Reck M, O'Byrne KJ, Geese WJ, Green G, Chang H, Szustakowski J, Bhagavatheeswaran P, Healey D, Fu Y, Nathan F and Paz-Ares L: Nivolumab plus ipilimumab in lung cancer with a high tumor mutational burden. N Engl J Med 378(22): 2093-2104, 2018. PMID: 29658845. DOI: 10.1056/NEJMoa1801946

6 Mok TSK, Wu YL, Kudaba I, Kowalski DM, Cho BC, Turna HZ, Castro G, Srimuninnimit V, Laktionov KK et al.:
Pembrolizumab versus chemotherapy for previously untreated, pd-11-expressing, locally advanced or metastatic non-small-cell lung cancer (keynote-042): A randomised, open-label, controlled, phase 3 trial. Lancet 393(10183): 1819-1830, 2019. PMID: 30955977. DOI: 10.1016/S0140-6736(18)32409-7

7 Diem S, Kasenda B, Spain L, Martin-Liberal J, Marconcini R, Gore M and Larkin J: Serum lactate dehydrogenase as an early marker for outcome in patients treated with anti-pd-1 therapy in metastatic melanoma. Br J Cancer 114(3): 256-261, 2016. PMID: 26794281. DOI: 10.1038/bjc.2015.467

8 Simeone E, Gentilcore G, Giannarelli D, Grimaldi AM, Caraco C, Curvietto M, Esposito A, Paone M, Palla M, Cavalcanti E, Sandomenico F, Petrillo A, Botti G, Fulciniti F, Palmieri G, Queirolo P, Marchetti P, Ferraresi V, Rinaldi G, Pistillo MP, Ciliberto G, Mozzillo N and Ascierto PA: Immunological and biological changes during ipilimumab treatment and their potential correlation with clinical response and survival in patients with advanced melanoma. Cancer Immunol Immunother 63(7): 675683, 2014. PMID: 24695951. DOI: 10.1007/s00262-014-1545-8

9 Bagley SJ, Kothari S, Aggarwal C, Bauml JM, Alley EW, Evans TL, Kosteva JA, Ciunci CA, Gabriel PE, Thompson JC, Stonehouse-Lee S, Sherry VE, Gilbert E, Eaby-Sandy B, Mutale F, DiLullo G, Cohen RB, Vachani A and Langer CJ: Pretreatment neutrophil-to-lymphocyte ratio as a marker of outcomes in nivolumab-treated patients with advanced nonsmall-cell lung cancer. Lung Cancer 106: 1-7, 2017. PMID: 28285682. DOI: 10.1016/j.lungcan.2017.01.013

10 Diem S, Schmid S, Krapf M, Flatz L, Born D, Jochum W, Templeton AJ and Fruh M: Neutrophil-to-lymphocyte ratio (nlr) and platelet-to-lymphocyte ratio (plr) as prognostic markers in patients with non-small cell lung cancer (nsclc) treated with nivolumab. Lung Cancer 111: 176-181, 2017. PMID: 28838390. DOI: 10.1016/j.lungcan.2017.07.024

11 Tanizaki J, Haratani K, Hayashi H, Chiba Y, Nakamura Y, Yonesaka K, Kudo K, Kaneda H, Hasegawa Y, Tanaka K, Takeda M, Ito A and Nakagawa K: Peripheral blood biomarkers associated with clinical outcome in non-small cell lung cancer patients treated with nivolumab. J Thorac Oncol 13(1): 97-105, 2018. PMID: 28838390. DOI: 10.1016/j.lungcan.2017.07.024

12 Tamiya M, Tamiya A, Inoue T, Kimura M, Kunimasa K, Nakahama K, Taniguchi Y, Shiroyama T, Isa SI, Nishino K, Kumagai T, Suzuki H, Hirashima T, Atagi S and Imamura F: Metastatic site as a predictor of nivolumab efficacy in patients with advanced non-small cell lung cancer: A retrospective multicenter trial. PLoS One 13(2): e0192227, 2018. PMID: 29470536. DOI: 10.1371/journal.pone.0192227

13 Weber JS, Hodi FS, Wolchok JD, Topalian SL, Schadendorf D, Larkin J, Sznol M, Long GV, Li H, Waxman IM, Jiang J and Robert C: Safety profile of nivolumab monotherapy: A pooled analysis of patients with advanced melanoma. J Clin Oncol 35(7): 785-792, 2017. PMID: 28068177. DOI: 10.1200/JCO.2015.66.1389

14 Brahmer J, Reckamp KL, Baas P, Crino L, Eberhardt WE, Poddubskaya E, Antonia S, Pluzanski A, Vokes EE, Holgado E, Waterhouse D, Ready N, Gainor J, Aren Frontera O, Havel L, Steins M, Garassino MC, Aerts JG, Domine M, Paz-Ares L, Reck M, Baudelet C, Harbison CT, Lestini B and Spigel DR: Nivolumab versus docetaxel in advanced squamous-cell nonsmall-cell lung cancer. N Engl J Med 373(2): 123-135, 2015. PMID: 26028407. DOI: 10.1056/NEJMoa1504627 
15 Lee CK, Man J, Lord S, Links M, Gebski V, Mok T and Yang JC: Checkpoint inhibitors in metastatic egfr-mutated non-small cell lung cancer-a meta-analysis. J Thorac Oncol 12(2): 403-407, 2017. PMID: 27765535. DOI: 10.1016/j.jtho.2016.10.007

16 Haratani K, Hayashi H, Chiba Y, Kudo K, Yonesaka K, Kato R, Kaneda H, Hasegawa Y, Tanaka K, Takeda M and Nakagawa K: Association of immune-related adverse events with nivolumab efficacy in non-small-cell lung cancer. JAMA Oncol 4(3): 374378, 2018. PMID: 28975219. DOI: 10.1001/jamaoncol.2017.2925

17 Shaul ME and Fridlender ZG: Neutrophils as active regulators of the immune system in the tumor microenvironment. J Leukoc Biol 102(2): 343-349, 2017. PMID: 28264904. DOI: 10.1189/jlb.5MR1216-508R

18 Liang W and Ferrara N: The complex role of neutrophils in tumor angiogenesis and metastasis. Cancer Immunol Res 4(2): 83-91, 2016. PMID: 26839309. DOI: 10.1158/2326-6066.CIR-15-0313

19 Nakamura S, Hayashi K, Imaoka Y, Kitamura Y, Akazawa Y, Tabata K, Groen R, Tsuchiya T, Yamasaki N, Nagayasu T and Fukuoka J: Intratumoral heterogeneity of programmed cell death ligand-1 expression is common in lung cancer. PLoS One 12(10): e0186192, 2017. PMID: 29049375. DOI: 10.1371/journal.pone.0186192

20 Chan-Young Ock SK, Bhumsuk Keam, Soyeon Kim, Yong-Oon Ahn, Eun-Jae Chung, Jin-Ho Kim, Tae Min Kim, Seong Keun Kwon, Yoon Kyung Jeon, Kyeong Chun Jung, Dong-Wan Kim, Hong-Gyun Wu, Myung-Whun Sung and Dae Seog Heo: Changes in programmed death-ligand 1 expression during cisplatin with head nad neck squamous cell carcinoma. Oncotarget 8(58): 97920-97927, 2017. PMID: 29228662. DOI: 10.18632 /oncotarget.18542

21 Guibert N, Delaunay M, Lusque A, Boubekeur N, Rouquette I, Clermont E, Mourlanette J, Gouin S, Dormoy I, Favre G, Mazieres J and Pradines A: Pd-11 expression in circulating tumor cells of advanced non-small cell lung cancer patients treated with nivolumab. Lung Cancer 120: 108-112, 2018. PMID: 29748004. DOI: 10.1016/j.lungcan.2018.04.001

22 Okuma Y, Wakui H, Utsumi H, Sagawa Y, Hosomi Y, Kuwano $\mathrm{K}$ and Homma S: Soluble programmed cell death ligand 1 as a novel biomarker for nivolumab therapy for non-small-cell lung cancer. Clin Lung Cancer 19(5): 410-417 e411, 2018. PMID: 29859759. DOI: 10.1016/j.cllc.2018.04.014

23 Kanai T, Suzuki H, Yoshida H, Matsushita A, Kawasumi H, Samejima Y, Noda Y, Nasu S, Tanaka A, Morishita N, Hashimoto S, Kawahara K, Tamura Y, Okamoto N, Tanaka T and Hirashima T: Significance of quantitative interferon-gamma levels in non-small-cell lung cancer patients' response to immune checkpoint inhibitors. Anticancer Res 40(5): 2787-2793, 2020. PMID: 32366425. DOI: 10.21873/anticanres.14251

24 Tanaka R, Okiyama N, Okune M, Ishitsuka Y, Watanabe R, Furuta J, Ohtsuka M, Otsuka A, Maruyama H, Fujisawa Y and Fujimoto M: Serum level of interleukin-6 is increased in nivolumab-associated psoriasiform dermatitis and tumor necrosis factor- $\alpha$ is a biomarker of nivolumab recativity. J Dermatol Sci 86(1): 71-73, 2017. DOI: 10.1016/j.jdermsci.2016.12.019

25 Botticelli A, Cerbelli B, Lionetto L, Zizzari I, Salati M, Pisano A, Federica M, Simmaco M, Nuti M and Marchetti P: Can IDO activity predict primary resistance to anti-PD-1 treatment in NSCLC? J Translat Med 16(1): 219, 2018. PMID: 30081936. DOI: $10.1186 / \mathrm{s} 12967-018-1595-3$

26 Jeyakumar G, Kim S, Bumma N, Landry C, Silski C, Suisham $\mathrm{S}$, Dickow B, Heath E, Fontana $\mathrm{J}$ and Vaishampayan U:
Neutrophil lymphocyte ratio and duration of prior antiangiogenic therapy as biomarkers in metastatic rcc receiving immune checkpoint inhibitor therapy. J Immunother Cancer 5(1): 82, 2017. PMID: 29041991. DOI: 10.1186/s40425-017-0287-5

27 Lalani AA, Xie W, Martini DJ, Steinharter JA, Norton CK, Krajewski KM, Duquette A, Bosse D, Bellmunt J, Van Allen EM, McGregor BA, Creighton CJ, Harshman LC and Choueiri TK: Change in neutrophil-to-lymphocyte ratio (nlr) in response to immune checkpoint blockade for metastatic renal cell carcinoma. J Immunother Cancer 6(1): 5, 2018. PMID: 29353553. DOI: $10.1186 / \mathrm{s} 40425-018-0315-0$

28 Lee CK, Man J, Lord S, Cooper W, Links M, Gebski V, Herbst RS, Gralla RJ, Mok $\mathrm{T}$ and Yang JC: Clinical and molecular characteristics associated with survival among patients treated with checkpoint inhibitors for advanced non-small cell lung carcinoma: A systematic review and meta-analysis. JAMA Oncol 4(2): 210216, 2018. PMID: 29270615. DOI: 10.1001/jamaoncol.2017.4427

29 Freeman-Keller M, Kim Y, Cronin H, Richards A, Gibney G and Weber JS: Nivolumab in resected and unresectable metastatic melanoma: Characteristics of immune-related adverse events and association with outcomes. Clin Cancer Res 22(4): 886-894, 2016. PMID: 26446948. DOI: 10.1158/1078-0432.CCR-15-1136

30 Buder-Bakhaya K, Benesova K, Schulz C, Anwar H, Dimitrakopoulou-Strauss A, Weber TF, Enk A, Lorenz HM and Hassel JC: Characterization of arthralgia induced by pd-1 antibody treatment in patients with metastasized cutaneous malignancies. Cancer Immunol Immunother 67(2): 175-182, 2018. PMID: 29018908. DOI: 10.1007/s00262-017-2069-9

31 Kleijn S, Langereis J, Leentjens J, Kox M, Netea M, Koenderman L, Ferwerda G, Pickkers P and Hermans P: IFN- $\gamma$ stimulated neutrophils suppress lymphocyte proliferation through expression of PD-L1. PLoS One 8(8): e72249, 2013. DOI: 10.1371/journal.pone.0072249

32 Zhong C, Qu X, Tan M, Meng YG and Ferrara N: Characterization and regulation of bv8 in human blood cells. Clin Cancer Res 15(8): 2675-2684, 2009. PMID: 19336519. DOI: $10.1158 / 1078-0432 . C C R-08-1954$

33 Kalluri $\mathrm{R}$ and Weinberg RA: The basics of epithelialmesenchymal transition. J Clin Invest 119(6): 1420-1428, 2009. PMID: 19487818. DOI: 10.1172/JCI39104

34 Ardi VC, Kupriyanova TA, Deryugina EI and Quigley JP: Human neutrophils uniquely release timp-free mmp-9 to provide a potent catalytic stimulator of angiogenesis. Proc Natl Acad Sci USA 104(51): 20262-20267, 2007. PMID: 18077379. DOI: 10.1073/pnas.0706438104

35 Knaapen AM, Gungor N, Schins RP, Borm PJ and Van Schooten FJ: Neutrophils and respiratory tract dna damage and mutagenesis: A review. Mutagenesis 21(4): 225-236, 2006. PMID: 16870698. DOI: 10.1093/mutage/gel032

36 Ritchie G GH, Man J, Lord S, Marschner I, Friedlander M and Lee CK: Defining the most appropriate primary end point in phase 2 trials of immune checkpoint inhibitors for advanced solid cancers: A systematic review and meta-analysis. JAMA Oncol 4(4): 522-528, 2018. PMID: 29470579. DOI: $10.1001 /$ jamaoncol.2017.5236

Received May 10, 2020

Revised May 28, 2020

Accepted May 31, 2020 